\title{
Determination of Refractory Trace Elements in Chinese Meteorites by RNAA
}

\author{
By URS KRAHENBOHL and MARIo BURger, Laboratorium für Radiochemie, Universität Bern, 3000 Bern 9, \\ Switzerland
}

Dedicated to Prof. Hans Rudolf von Gunten on the occasion of his $60^{\text {th }}$ birthday

(Received July 4, 1988; revised September 6, 1988)

Activation analysis / Radiochemical separation/Yttrium / Lewatite resin/Extraction with D2EHPA

\begin{abstract}
Some refractory trace elements are important target elements for spallation reactions in meteorites. These elements also serve to characterize the investigated meteorites. The elements $\mathrm{Ti}, \mathrm{Y}, \mathrm{Zr}$, $\mathrm{Hf}, \mathrm{W}$ and $\mathrm{Ta}$ were measured after radiochemical separation in chondrites from China. After acid digestion of the irradiated samples, the group separations were obtained by precipitation reactions. The necessary radiochemical purification of the pure $\beta$ emitter $Y$ was realized on a Lewatite OC 1026 column. For all the other elements discrete gamma radiation was measured.
\end{abstract}

\section{Introduction}

Recently a large number of meteorites from China became available for investigations [1]. Due to the dense population of this huge country (about $7 \%$ of the land surface of the earth) many falls of such precious stones are observed and some material is collected every year. The chemical composition is important for the characterization of the meteorite as well as for a complete study of the history of the investigated fragments and for noble gas studies. Many rarely determined elements are important target elements for spallation reactions by the cosmic radiation. $\mathrm{Y}$ and $\mathrm{Zr}$ contribute to the formation of $\mathrm{Kr}$ and $\mathrm{Ba}$ and rare earth elements to that of $\mathrm{Xe}$. The main fractions of the samples were used for a thorough study of the concentrations of the noble gases and a study of their isotopic composition [2]. The samples were provided by the Institute of Geochemistry, Academia Sinica, Beijing, to the Department of Physics of our university. The physicists themselves forwarded a small fraction of the material for direct chemical analyses of important elements to our laboratory.

The aim of this study is to present a sensitive method capable of determining low concentrations of elements not accessible by INAA, even in small samples.

\section{Experimental}

\section{Dissolution of samples}

The crushed meteoritic material was sealed in Suprasil vials (synthetic quartz) and irradiated for 2 days at a thermal flux of $5 \times 10^{13} \times \mathrm{s}^{-1} \mathrm{~cm}^{-2}$ in the swimming pool reactor SAPHIR at Würenlingen, Switzerland. After a cooling period of two days to reduce the level of activity, the gamma radiation of the samples were measured with a $\mathrm{Ge}(\mathrm{Li})$ detector connected to a multichannel system with a loss free counting unit (LFC) for the assessment of the concentrations of $\mathrm{Na}, \mathrm{Sc}, \mathrm{Cr}, \mathrm{Fe}$ and $\mathrm{Co}$. The quartz vials were then cut open and the samples were dissolved in presence of carriers of $\mathrm{Sc}, \mathrm{Zr}, \mathrm{W}$ and $\mathrm{Ta}$ and $1 \mathrm{mg} \mathrm{La}$ by addition of $8 \mathrm{ml}$ conc. HF and $4 \mathrm{ml}$ conc. $\mathrm{HClO}_{4}$ in teflon crucibles (see relevant information in Table 1). The residue was then boiled for 2 hours with $5 \mathrm{ml}$ of conc. $\mathrm{HNO}_{3}$. After the evaporation to the near dryness the residue was ready for group separations.

Table 1. Analysis parameters of the measured elements

\begin{tabular}{|c|c|c|c|c|c|c|}
\hline Element & Carrier & $\begin{array}{l}\text { Measured } \\
\text { radio- } \\
\text { nuclide }\end{array}$ & $\begin{array}{l}\text { Half } \\
\text { life } \\
h\end{array}$ & $\begin{array}{l}\text { Weighing } \\
\text { form }\end{array}$ & $\begin{array}{c}\text { Chemical } \\
\text { yield }\end{array}$ & $\begin{array}{c}\text { Measu red } \\
\text { energy } \\
\text { keV }\end{array}$ \\
\hline $\mathbf{T i}$ & Sc: $5 \mathrm{mg}$ & Sc-48 & 43.7 & $\operatorname{Sc}(\mathrm{D} 2 \mathrm{EHPA})_{\mathrm{n}}$ & & $\begin{array}{l}1312 \\
1037\end{array}$ \\
\hline $\mathbf{Y}$ & $\begin{array}{c}\text { carrier } \\
\text { free }\end{array}$ & $Y .90$ & 64.1 & $Y$ oxinate & $\begin{array}{l}Y-88 \\
50 \%\end{array}$ & $\beta^{-}$ \\
\hline $\mathbf{Z r}_{\mathbf{r}}$ & $\mathrm{s}-7 \mathrm{mg}$ & $\mathrm{Zr}-95$ & 1545 & $\mathrm{Zr}$ mandelate & $85 \%$ & $\begin{array}{l}724 \\
756\end{array}$ \\
\hline $\mathrm{Ta}$ & $20 \mathrm{mg}$ & Ta-182 & 2746 & $\mathrm{Ta}_{2} \mathrm{O}_{5}$ & $60 \%$ & $\begin{array}{l}1189 \\
1221\end{array}$ \\
\hline Hf & $\begin{array}{c}\text { coprecipi- } \\
\text { tation }\end{array}$ & Hf- 181 & 1020 & Hf mandelate & $85 \%$ & $\begin{array}{l}482 \\
346\end{array}$ \\
\hline w & $20 \mathrm{mg}$ & $W-187$ & 23.9 & $\mathrm{WO}_{3}$ & $60 \%$ & $\begin{array}{l}686 \\
480\end{array}$ \\
\hline
\end{tabular}




\section{Group separation}

A schematic representation of the chemical procedure is given in Fig. 1. The precipitate formed after the dissolution and treatment with $\mathrm{HNO}_{3}$ contains $\mathrm{WO}_{3} \cdot \mathbf{n}\left(\mathrm{H}_{2} \mathrm{O}\right)$ and $\mathrm{Ta}_{2} \mathrm{O}_{5} \cdot \mathrm{n}\left(\mathrm{H}_{2} \mathrm{O}\right)$, which are separated by centrifugation. In the supernate, the hydroxides are precipitated with conc. $\mathrm{NH}_{3}$. The hydroxides are redissolved in $2 \mathrm{ml}$ conc. $\mathrm{HCl}$ and loaded onto an anion exchange column (Dowex $2 \times 8,200-400$ mesh, diameter $6 \mathrm{~mm}$, length $100 \mathrm{~mm}$ ). REE, Y and $\mathrm{Sc}$ do not stick to the resin in $10 \mathrm{M} \mathrm{HCl}$ acid. $\mathrm{Zr}$ and $\mathrm{Hf}$ are eluted with $25 \mathrm{ml} 6 \mathrm{M} \mathrm{HCl}$. The REE are again precipitated as hydroxides and redissolved with $0.05 \mathrm{M} \mathrm{HNO}_{3} .1 \mathrm{mg}$ each of $\mathrm{Tb}$ and $\mathrm{Sm}$ carriers are added. The resulting solution is placed on a column filled with Lewatite OC 1026 (Bayer AG, Leverkusen) [3]. This resin is produced by copolymerization of D2EHPA (di-2ethyl hexyl phosphate) with styrene and divinyl benzene and has favourable properties for metal separations $[4,5]$. Columns of a diameter of $4 \mathrm{~mm}$ and a length of $120 \mathrm{~mm}$ were filled with this resin using a grain size fraction 0.12 to $0.17 \mathrm{~mm}$. From such columns La elutes in the first $40 \mathrm{ml}$ of $0.5 \mathrm{M} \mathrm{HNO}_{3}$. In the next $60 \mathrm{ml}$ of $1 \mathrm{M} \mathrm{HNO}_{3}$. Eu elutes as the main activity. $\mathrm{Y}$ is finally eluted with $40 \mathrm{ml} 1.5 \mathrm{M} \mathrm{HNO}_{3}$, whereas Sc remains on the Lewatite resin.

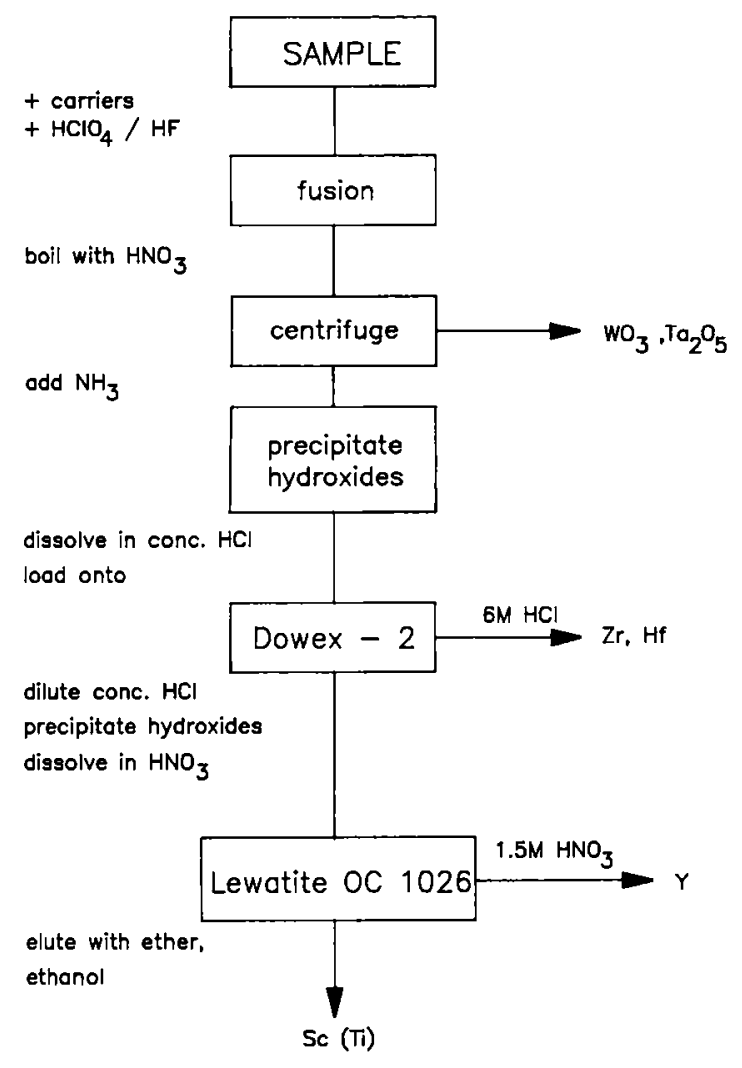

Purification of the elements

Hf: see $\mathrm{Zr}$. This element follows so closely the chemical behaviour of $\mathrm{Zr}_{\mathrm{r}}$ that only $\mathrm{Zr}$ carrier is used as group carrier $[6,7]$. The chemical yield obtained for $\mathrm{Zr}$ is assumed to be valid also for $\mathrm{Hf}$.
Ta: The residue after the dissolution of $W$ is transferred to tubes of polyethylene. Ta is then immediately dissolved by 10M HF [8] (after a few hours the dissolution will not work any more). The resulting solution is extracted into diethylether giving the necessary decontamination from $\mathrm{Fe}$ and $\mathrm{Cr}[9]$. The ether is evaporated and the residue filtered off onto paper discs and dryed. After the measurement of the activity the samples are calcinated and the $\mathrm{Ta}_{2} \mathrm{O}_{5}$ weighed for the determination of the chemical yield. (When filter discs of quartz fibres are used, the calcination at $800^{\circ} \mathrm{C}$ can be done before the counting.)

Ti: Since Ti only forms short lived nuclides by the irradiation with thermal neutrons, the fast neutron reaction $(n, p)$ producing ${ }^{48} \mathrm{Sc}$ allows to dose this element a few days after the irradiation with reactor neutrons. $\mathrm{Sc}$ is very strongly retained by the Lewatite resin [10]. After the elution of $\mathrm{Y}$ from the columns, the resin is transformed to the chloride form with $5 \mathrm{ml}$ of $6 \mathrm{M} \mathrm{HCl}$. The columns are next washed with $10 \mathrm{ml}$ ether. This eluate is collected in centrifuge tubes containing $1 \mathrm{ml}$ of $6 \mathrm{M}$ $\mathrm{HCl}$. After the evaporation of the ether on a water bath, the Lewatite columns are washed with $10 \mathrm{ml}$ ethanol, which is collected in the same centrifuge tubes. White flakes precipitate (probably Sc(D2EHPA) $)_{3}$ ) [4], which can be filtered off after 5 to 10 minutes onto glass fibre discs and washed with $30 \mathrm{ml}$ water. The precipitate is dryed at $105^{\circ} \mathrm{C}$ and reaches constant weight after 3 hours.

W: The freshly formed precipitate is heated with $25 \%$ solution of ammonia to dissolve W [11]. Only about one half of the $W$ dissolves. The remaining $W$ is then dissolved with $5 \mathrm{ml}$ conc. $\mathrm{HCl}$. The resulting solution is combined with the solution of $\mathrm{NH}_{3} \cdot \mathrm{WO}_{3} \cdot \mathrm{xH}_{2} \mathrm{O}$ is reprecipitated by warming with $2 \mathrm{ml}$ of conc. $\mathrm{HNO}_{3}$. The $\mathrm{WO}_{3} \cdot \mathrm{n}\left(\mathrm{H}_{2} \mathrm{O}\right)$ precipitate is directly filtered onto paper filter discs. The chemical yield is determined after the measurement of the activity. Since the precipitate has no stochiometric composition it needs calcination prior to the weighing.

Y: To the eluted solution from the Lewatite column containing the $Y, 10 \mathrm{mg}$ of $Y$ carrier are added. The hydroxide is precipitated with $\mathrm{NH}_{3}$, separated by centrifugation and dissolved with $4 \mathrm{ml}$ of $6 \mathrm{M} \mathrm{HCl}$. After dilution to $2 \mathrm{M} \mathrm{HCl}$, the final precipitate is obtained by the addition of $5 \mathrm{ml}$ of a $5 \%$ oxinate solution. The resulting sample is radiochemically pure. The chemical yield is determined by the measurement of ${ }^{88} \mathrm{Y}$, added to the sample prior to dissolution. The $\beta$ activity is measured on a proportional counter using an $\mathrm{Al}$ absorber of $677 \mathrm{mg} /$ $\mathrm{cm}^{2}$. The decay of ${ }^{90} \mathrm{Y}$ is followed. The necessary correction for the contribution of ${ }^{88} \mathrm{Y}$ and contaminates is less then $5 \%$ of the counts in the $\beta$ channel.

$\mathbf{Z r}$ : This element is eluted from the anion resin together with Hf using $25 \mathrm{ml}$ of $6 \mathrm{M} \mathrm{HCl}[6,7]$. The eluate is combined with $20 \mathrm{ml}$ of a saturated mandelic acid solution. $\mathrm{Hf}$ and $\mathrm{Zr}$ both precipitate as the mandelate. They are filtered off, and washed with water and ether. 
Table 2a. Major and trace elements measured by instrumental activation analysis ( $1 \sigma$ errors are $\pm 10 \%)$

\begin{tabular}{lcccccc}
\hline $\begin{array}{l}\text { Chondritic } \\
\text { meteorite }\end{array}$ & $\begin{array}{c}\text { Meteorite } \\
\text { type }\end{array}$ & $\begin{array}{c}\text { Na } \\
\text { ppm }\end{array}$ & $\begin{array}{c}\text { Sc } \\
\text { ppm }\end{array}$ & $\begin{array}{c}\text { Cr } \\
\text { ppm }\end{array}$ & $\begin{array}{c}\text { Co } \\
\text { ppm }\end{array}$ & $\begin{array}{c}\mathrm{Fe} \\
\%\end{array}$ \\
\hline Guangnan & L6 & 6300 & 6.6 & 3180 & 1160 & 23.7 \\
Xingyang & H5 & 5700 & 6.3 & 3500 & 840 & 24.6 \\
\hline
\end{tabular}

Table 2b. Trace elements determined by radiochemical neutron activation analysis $(1 \sigma$ errors: $\mathrm{Ti} \pm 15 \%, \mathrm{Y} \pm 10 \%, \mathrm{Zr}, \mathrm{Hf}, \mathrm{W}$ and $\mathrm{Ta} \pm 5 \%$ )

\begin{tabular}{lccccccc}
\hline $\begin{array}{l}\text { Chondritic } \\
\text { meteorite }\end{array}$ & $\begin{array}{c}\text { Meteorite } \\
\text { type }\end{array}$ & $\begin{array}{c}\mathrm{Ti} \\
\mathrm{ppm}\end{array}$ & $\begin{array}{c}\mathrm{Y} \\
\mathrm{ppm}\end{array}$ & $\begin{array}{c}\mathrm{Zr} \\
\mathrm{ppm}\end{array}$ & $\begin{array}{c}\mathrm{Hf} \\
\mathrm{ppm}\end{array}$ & $\begin{array}{c}\mathrm{W} \\
\mathrm{ppm}\end{array}$ & $\begin{array}{c}\mathrm{Ta} \\
\mathrm{ppm}\end{array}$ \\
\hline Guangnan & $\mathrm{L} 6$ & - & 2.2 & 5.7 & 0.12 & 0.50 & - \\
Xingyang & $\mathrm{H} 5$ & - & 2.2 & 5.2 & 0.08 & - & - \\
Xingyang & $\mathrm{H} 5$ & $\leqslant 600$ & 2.1 & 5.3 & 0.08 & 0.85 & 0.024 \\
Average & $\mathrm{L} 6$ & $460-810^{\mathrm{a}}$ & $2.1^{\mathrm{a}}$ & $5.1 \mathrm{~b}$ & $0.14 \mathrm{~b}$ & $0.12^{\mathrm{a}}$ & $0.021^{\mathrm{a}}$ \\
chondrites & $\mathrm{H} 5$ & $510-780^{\mathrm{a}}$ & $2.2^{\mathrm{a}}$ & $6.2 \mathrm{~b}$ & $0.23 \mathrm{~b}$ & $\mathbf{0 . 1 4}$ & $0.021^{\mathrm{a}}$ \\
BHVO-1 & & 15200 & 28.1 & 190 & 4.3 & 0.26 & 1.0 \\
BHVO-1 Lit.c & & 16000 & 28 & 180 & 4.2 & 0.28 & 1.1 \\
& & \pm 500 & \pm 2 & \pm 30 & \pm 0.2 & & \pm 0.2 \\
\hline
\end{tabular}

a MASON [12]

b EHMANN and REBAGAY [13]

c Geostandards Newsietter [14]

\section{Results and discussion}

Table 2a contains the results of the measurements of the gamma radiation prior to dissolution of the samples for the meteorites investigated in this study. Only elements important for the chemical characterization are reported here. A distinct difference in composition is recognized between the two meteorites. As expected the concentration for $\mathrm{Fe}$ is higher for Xingyang (type $\mathrm{H} 5$, high iron chondrite) compared to Guangnan a L6 chondrite, whereas the concentration for $\mathrm{H}$ chondrites is lower compared to L chondrites for Na. As this paper mainly deals with the radiochemical determination of elemental concentrations, the results in Table $2 \mathrm{~b}$ will be discussed more extensively. To demonstrate the reproducibility of the procedure, the values obtained for Xingyang in two different experimental series are reported individually. Excellent agreement between the two sets indicates good control of the chemical treatment of the samples. The elements $\mathrm{Ti}, \mathrm{W}$ and Ta were added in the development of the chemical procedure, therefore only one value is reported for these three elements for the chondrite Xingyang. No results are reported in the literature for the radiochemically investigated elements of the analyzed meteorites. The results presented lie in the range for chondrites published by MASON [12], excepting those for $W$. Our values for $W$ are very high compared to the average reported by MASON. However, our control results for the US Geological Survey reference material BHVO-1, analyzed simultaneously, are identical to those reported in the literature. Often, $W$ is analyzed by instrumental techniques known to be more prone to contributions from other gamma lines, than our radiochemical method.
The sensitivity for $\mathrm{Ti}$ is rather low. Concentrations below $0.1 \%$ are difficult to assess by the technique presented here. For meteorites originating from the earth's moon, which have concentrations of $\mathrm{Ti}$ in the percent level, good results were obtained [15]. The value for BHVO-1 coincides within the error with the one reported in the literature.

The presented results in combination with noble gas data allow to derive specific $\mathrm{Kr}$ production rates for $\mathrm{Y}$ and $\mathrm{Zr}$ [16]. $\mathrm{Y}$ and $\mathrm{Zr}$ concentrations and the resulting production rates strongly vary among different meteorite classes. Therefore, the element specific production rates have to be known for the calculation of cosmic ray exposure ages of extraterrestrial samples [17].

\section{Acknowledgment}

We thank O. EUGSTER for organizing the joint investigation of the meteorite samples. We are greatly indebted to D. WANG, TU KWANGCHIH and CH. SHEN for providing the investigated Chinese meteorite samples. This work was supported in part by the Swiss National Science Foundation and by the Stipendienfonds der Basler Chemischen Industrie. The manuscript was improved by RICHARD KNOCHENMUSS.

\section{References}

1. WANG, D., RUBIN, A. E.: Meteoritics 22, 97 (1987).

2. EUGSTER, O., MICHEL, TH., NIEDERMANN, S. Meteoritics 23, 25 (1988). 
3. Bayer AG Leverkusen Produkt-Information Lewatite OC 1026.

4. WINCHESTER, J. W.: J. Chromatogr. 10, 502 (1963)

5. PEPPARD, D. F.: J. Inorg. Nucl. Chem. 30, 3305 (1968).

6. National Academy of Sciences NAS-NS 3011 , ed. STEINBERG, E. P. (1960)

7. HoffmaN, E. H., IDdings, G. N., LILLY, R. C.: J. Am. Chem. Soc. 73, 4474 (1951).

8. National Academy of Sciences NAS-NS 3039, ed. STEIN. BERG, E. P. (1961).

9. BOCK, R., HERRMANN, M.: Z. Anorg. Allg. Chem. 284, 28 (1956)
10. National Academy of Sciences NAS-NS 3020, ed. STEVENSON, P. C., NEWIK, W. E. (1961).

11. National Academy of Sciences NAS-NS 3042, ed. MULLINS, W. T., LEDDICOTTE, G. W. (1961).

12. Handbook of elemental abundances in meteorites, ed. MASON, B. (1971)

13. EHMANN, W. M., REBAGAY, T. V.: Geochim. Cosmochim. Acta 34, 649 (1970).

14. Geostandards Newsletters 5 (1981).

15. BURGER, M., KR ÄHENBÜHL, U., to be published.

16. REGNIER, S., HOHENBERG, C. M., MARTI, K., REEDY, R. C.: Proc. Lunar Planet. Scj. Conf. 10th 1565 (1979).

17. EUGSTER, O.: Geochim. Cosmochim. Acta 52, 1649 (1988). 